\title{
Metabolismo urbano DE NUTRIENTES: REÚSO Y COMPOSTAJE DE RESIDUOS ASOCIADOS CON LA PORCICULTURA EN Ciudad JuÁrez ${ }^{\text {I }}$
}

VÍCTOR HUGO ZAMORA PADILLA² / ANA CÓRDOVA Y VÁZOUEZ ${ }^{3}$

\section{RESUMEN}

S e documentan las prácticas de manejo y los volúmenes de residuos orgánicos asociados con la porcicultura periurbana (escamocha y excretas), así como el manejo de las podas municipales que permitirían cerrar ciclos biogeoquímicos en Ciudad Juárez. Se determinó que, con 177 toneladas al año, existen suficientes podas municipales para compostar las 1967 toneladas anuales de excretas porcinas generadas, y que existe tanto la necesidad como la superficie suficiente para utilizar ese compost en las áreas verdes municipales. En este análisis parcial del metabolismo urbano de la ciudad, se demuestra que se tienen cubiertos los requisitos para el establecimiento del proceso de compostaje

1 Agradecemos al Conacyt por la beca de posgrado para uno de los autores; a los entrevistados por compartir generosamente su tiempo e información; y a los dictaminadores anónimos por sus valiosas aportaciones y sugerencias.

2 Profesor de asignatura en la Universidad Tecnológica de Ciudad Juárez (UTCJ), México. Correo electrónico: victorhzp87@gmail.com.

3 Profesora investigadora de El Colegio de la Frontera Norte en Ciudad Juárez. Mexico. Correo electrónico: acordova@colef.mx. 
en la localidad (el interés de los actores, la experiencia en el proceso, la infraestructura mínima).

Palabras clave: composta; flujos, metabolismo, sustentabilidad urbana, residuos sólidos urbanos.

\section{INTRODUCCIÓN}

El manejo inadecuado de los residuos sólidos urbanos (RSU) es uno de los grandes problemas ambientales de nuestro país (Semarnat, 2008). Este fenómeno crea una gama de problemas ambientales y de salud pública que tienen consecuencias económicas y sociales severas (Semarnat, 2008; Gobierno del Estado de Chihuahua, 2012). Gran parte de esta problemática tiene su raíz en paradigmas de planeación, operación y desarrollo urbano basados en un metabolismo lineal, en el que las ciudades se suministran de grandes cantidades de recursos naturales y descargan grandes cantidades de desechos sin existir procesos significativos de minimización o reutilización. Así, pues, se propone que la problemática de los residuos sólidos y otras que aquejan a las ciudades pueden atenderse efectivamente a través de un cambio de paradigma en la función urbana orientada hacia el cierre de ciclos naturales y el aumento de la circularidad del metabolismo urbano, reduciendo significativamente la huella ecológica urbana y promoviendo, con ello, la sostenibilidad.

Una estrategia para cerrar los ciclos naturales en la ciudad es el proceso de compostaje de residuos orgánicos, ya que al degradarlos y transformarlos en abono para el suelo, se generan y regeneran recursos naturales que proveen de servicios a la ciudad, reduciendo, entonces, las necesidades de suministro. A pesar del discurso de política pública que promueve la minimización y el aprovechamiento de los residuos, en México apenas se está iniciando el camino de la gestión integral de los residuos sólidos que priorice estos principios. Por ello, es necesario estudiar la posibilidad de llevar a cabo la transición hacia modelos de metabolismo urbano circular, por lo que esta investigación se enfoca en el aná- 
lisis de la viabilidad de compostaje en una localidad en particular. En este escrito, se presenta el análisis de los flujos de residuos orgánicos asociados con la porcicultura urbana, así como el manejo público de podas en Ciudad Juárez, Chihuahua, y se evalúa la factibilidad técnica y social de generar compost a partir de ellas.

Se estima que en México se generan 94800 toneladas diarias de RSU, de las cuales 12324 toneladas (13 \%) no se recolectan (Semarnat, 2008), por lo que se quedan circulando libremente en el ambiente. De las 82476 toneladas de Rsu recolectadas, solo $64 \%$ se enviaba a sitios controlados en 2005, mientras que el resto (29 691 toneladas diarias) se depositaba en tiraderos a cielo abierto o en sitios sin control (Semarnat, 2008), igualmente con posibilidades de circular libremente en poco tiempo. Esta insuficiencia de manejo de RSu ha llevado a que la Secretaría de Medio Ambiente y Recursos Naturales (Semarnat) en 2008 haya identificado la basura como uno de los asuntos más importantes de la problemática ambiental en nuestro país. Al ser una responsabilidad de las autoridades locales, la gestión de los residuos sólidos en nuestro país varía mucho de municipio a municipio y de acuerdo con la problemática local. Sin embargo, incluso en municipios como Juárez, Chihuahua, donde las estadísticas oficiales reportan los índices más altos de recolección y disposición de RSU (Gobierno del Estado de Chihuahua, 2012), se observan cotidianamente acumulaciones de basura en las calles y lotes baldíos de la ciudad. Asimismo, existen flujos de residuos urbanos que no están contabilizados (como los residuos pecuarios urbanos descritos en este trabajo, entre otros). Así que, a pesar de las estadísticas, existe un manejo inadecuado y/o insuficiente de RSU en prácticamente todas las localidades de nuestro país.

Para determinar la factibilidad de la implementación del proceso de compostaje en una localidad, es necesario, en primera instancia, caracterizar y determinar el flujo de residuos orgánicos en la misma, así como las prácticas de los principales actores que producen y manejan las cantidades aprovechables. A pesar de contar con un marco regulatorio amplio en materia de gestión de residuos sólidos, en México aún hay poco conocimiento sobre 
la cantidad y composición de los RSU (Buenrostro, \& Israde, 2003). En Ciudad Juárez, similarmente a diferentes municipios del país, falta conocimiento sobre datos de residuos orgánicos que permitan identificar estrategias que solucionen la problemática de los residuos en la ciudad.

El objetivo general de esta investigación es determinar el potencial para compostaje en Ciudad Juárez, identificando los flujos, volúmenes y manejo de ciertos residuos orgánicos, así como la demanda de compost en la localidad.

\section{MARCO TEÓRICO-CONCEPTUAL}

El análisis que aquí se presenta se enmarca en una serie de teorías y conceptos relativos al funcionamiento de las áreas urbanas y su interrelación con la naturaleza, con factores ambientales, así como con sus regiones proveedoras y receptoras. Estas teorías y conceptos incluyen, desde lo general hacia lo particular, ciclos biogeoquímicos, metabolismo circular en la naturaleza, ecosistemas urbanos, metabolismo urbano lineal y circular, huella ecológica, sostenibilidad, gestión ambiental, gestión integral de los RSU y las 3 R: reducción, reúso y reciclaje. A partir de este marco, se aborda el tema específico del compostaje en Ciudad Juárez, Chihuahua: concretamente el análisis de los flujos de residuos orgánicos asociados con la porcicultura urbana y el manejo de podas municipales, y la factibilidad técnica y social de instrumentarlo localmente. Entender el metabolismo urbano de residuos sólidos orgánicos y desarrollar estrategias, basadas en paradigmas holísticos, que puedan atender problemáticas ambientales, sociales y económicas derivadas de una gestión deficiente actual, contribuye directamente al desarrollo urbano en los ámbitos ambiental, económico y social.

Los ciclos biogeoquímicos son parte de la regulación del planeta, a través de sus sistemas complejos, e implican la circulación de la materia en forma sólida, líquida y/o gaseosa, a través de procesos biológicos, geológicos y/o químicos en medios atmosfériCos, acuáticos y terrestres del planeta (Odum, \& Sarmiento, 1998). 
Los ciclos implican así un flujo circular y repetitivo de elementos químicos que se mueven entre componentes vivos y no vivos de los ecosistemas, pasando de un estado orgánico a uno mineral y viceversa (Dajoz, 2002). Los ciclos del carbono (c), nitrógeno (N), fósforo (P) y potasio (K), se ven involucrados en el proceso de compostaje, el cual representa una actividad humana que replica, de forma intencional y generalmente óptima (acelerada), los ciclos biogeoquímicos en nuestro entorno (Marmolejo et al., 2009).

Las ciudades han sido conceptualizadas como ecosistemas urbanos y estudiadas como tales, analizando las relaciones y retroalimentaciones entre las decisiones humanas y los procesos ecológicos (Grimm \& Redman, 2004). Se ha postulado que, al igual que otras agrupaciones de organismos (Girardet, 1999), o similarmente a organismos individuales (Moughtin \& Shirley, 2005), las ciudades tienen un metabolismo definido, determinado por los flujos de energía y materia a través de ellos, y que la sostenibilidad urbana requiere de la orientación hacia metabolismos circulares similares a los que ocurren en la naturaleza (Girardet, 1999). En un metabolismo circular, los desechos de algunos procesos se convierten en insumos para otros (Girardet, 1999). La propuesta de metabolismo circular se contrasta con el metabolismo lineal que tienen las ciudades cuando consumen recursos y descargan desechos a sus regiones asociadas sin buscar cerrar ciclos localmente, como se ilustra en la figura 1.

\section{Figura 1. Esquema de metabolismo urbano lineal}

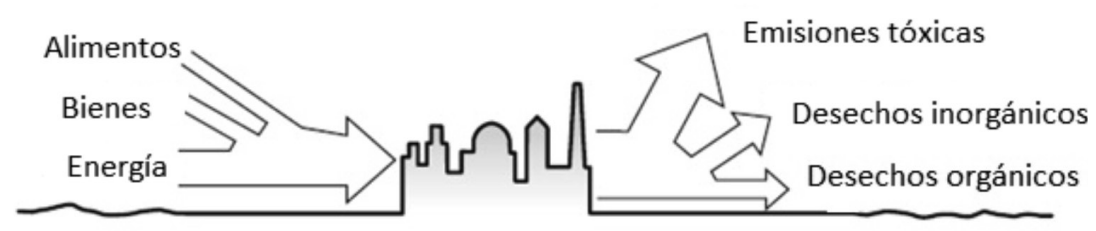

Fuente: Moughtin y Shirley (2005); traducción propia. 
Con esta conceptualización se entiende cómo es que las ciudades son el motor del consumo y del desecho de los recursos naturales (agua, materiales, energía, alimentos, suelos, biodiversidad) de sus regiones circundantes, y una fuerza determinante de la degradación ambiental en las zonas naturales que las sustentan. Este impacto también se formula a través del concepto de huella ecológica, que mide la superficie terrestre o capital natural necesarios para proveer a una unidad territorial u organizacional -en este caso una ciudad- los recursos que requiere para sobrevivir, así como para absorber las descargas que genera (Wackernagel, \& Rees, 1996). En este contexto, una condición básica para la sostenibilidad de los asentamientos humanos es reducir su huella ecológica, saneando y equilibrando el metabolismo urbano (los recursos que absorbe de, y los que descarga a, sus entornos cercanos y distantes). La figura 2 ilustra la reducción en insumos y descargas de una urbe que genera procesos de metabolismo circular, cerrando ciclos biogeoquímicos dentro de su propio territorio.

Figura 2. Esquema de metabolismo urbano circular

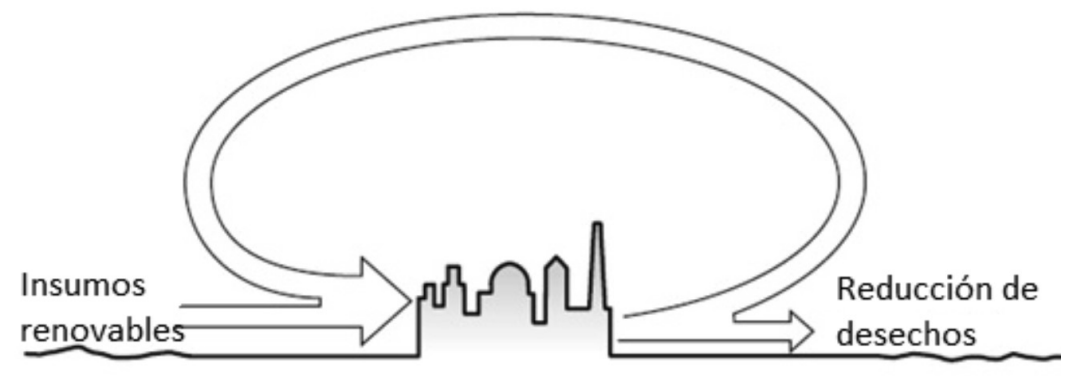

Fuente: Moughtin y Shirley (2005); traducción propia.

El compostaje presenta el potencial para transformar los residuos orgánicos de diversas actividades humanas urbanas en un abono para el suelo y, por lo tanto, un insumo para otros procesos ecológicos, incluida la producción vegetal. De esta manera, recircula estos productos dentro del territorio y ecosistema urbanos, y cierra el ciclo urbano de los nutrientes. 
Dentro de las propuestas y modelos de gestión ambiental, se ubica la gestión integral de residuos sólidos urbanos (GIRSU) que promueve los principios de prevención y minimización de residuos, así como su aprovechamiento y valoración (Semarnat, 2008). Esta propuesta también se ha presentado a través de las llamadas 3 R (reducción, reúso y reciclaje), que representan la jerarquía de estrategias para el manejo de los residuos. Indican que la prioridad debe darse a la reducción sobre el reúso y de este sobre el reciclaje, dejando la disposición final de los residuos como última alternativa para cuando se hayan agotado las oportunidades de las primeras tres estrategias (Rodríguez \& Córdova, 2006).

Dentro de las estrategias de reciclaje, concretamente de los residuos orgánicos, se ubica el proceso de compostaje, que es un procedimiento de descomposición aeróbica de la materia orgánica -un proceso controlado en el que se optimizan las condiciones que requieren los organismos descomponedores para desarrollar su función y que incluyen primordialmente una relación determinada de C, N, humedad y oxígeno (o) (Rodríguez \& Córdova, 2006).

\section{ENFOQUE Y ALCANCE DE LA INVESTIGACIÓN}

Ahora bien, a pesar de los principios rectores de la GIRSU, las 3 R y los demás planteamientos descritos hasta aquí, la realidad es que la mayor parte del metabolismo urbano en México y el mundo es lineal, y esto incluye el manejo de los residuos sólidos en general y de los orgánicos en particular. Cambiar los paradigmas de planeación, organización y desarrollo urbanos no es tarea sencilla ni automática. Por ello, es necesario estudiar la viabilidad de hacer la transición hacia modelos de metabolismo urbano circular, por lo que esta investigación se enfoca en el análisis de la factibilidad de compostaje en una localidad en particular. La factibilidad la entendemos como dependiente de cuestiones técnicas, sociales y económicas. Aquí se presentan las valoraciones de factibilidad técnica y social. Si bien hay varias fuentes de residuos orgánicos en la ciudad (domicilios, comercios, servicios, industrias, incluyendo plantas de tratamiento de aguas residuales, rastros, opera- 
ciones agropecuarias, así como podas y otros flujos no-infecciosos y no-tóxicos), el enfoque aquí es en los flujos de las operaciones pecuarias de la porcicultura, así como en los flujos asociados con el manejo público de podas.

\section{METODOLOGÍA}

Debido a la falta de datos sobre volúmenes y composición de residuos orgánicos en la localidad, fue necesario generar datos de campo de los flujos de interés. Se hizo una consulta electrónica, así como visitas a oficinas locales de diversas dependencias gubernamentales (Secretaría de Agricultura, Ganadería, Desarrollo Rural, Pesca y Alimentación [Sagarpa] e Instituto Nacional de Estadística y Geografía [Inegi] del nivel federal; Parques y Jardines, Protección Civil, y Ecología del nivel municipal) en busca de datos oficiales sobre el número y ubicación de granjas porcícolas, número de animales, tipos y volúmenes de alimentos/residuos asociados, etcétera. A pesar de contar con información muy detallada en el Censo Agropecuario, el Inegi no tiene desglosada la información entre urbano, periurbano y rural, y no se definía qué proporción de las operaciones porcícolas censadas correspondían a nuestra área de estudio. La Sagarpa solo tenía datos de operaciones pecuarias rurales. Las áreas de Protección Civil y Ecología del Municipio y el Gobierno del Estado tampoco contaban con registros de esta información. Finalmente, tampoco fue posible encontrarla en la revisión de literatura local, estatal o regional.

Se procedió, entonces, a generar dicha información en campo para las operaciones de la porcicultura. A través de consultas con expertos, una serie de visitas de campo y muestreo de bola de nieve hasta lograr la saturación de la información, se identificaron cuatro zonas con granjas porcícolas en la ciudad. En ellas, se entrevistó a los operadores que se encontraron durante las visitas. También se registró el número de granjas sin operador en el momento de la visita para tener una estimación del número total de granjas, número de animales, así como extensión de las áreas ocupadas. Finalmente, se identificaron las granjas que ya estaban 
abandonadas, que darían indicios de la evolución histórica de la actividad localmente. Las entrevistas se apoyaron en una guía en la que se explicaba el interés por conocer las fuentes y destinos de los residuos orgánicos, aclarando que no estaban asociadas a algún registro oficial — de naturaleza regulatoria económica o sanitaria- y garantizando la absoluta confidencialidad de los datos ofrecidos. Se preguntó acerca de las fuentes, volúmenes y costos de alimento para los animales; acerca de la generación de excretas (volúmenes y manejo); y, finalmente, sobre el destino de la producción (venta de cerdos).

Para la estimación de los volúmenes de podas de áreas verdes públicas, se entrevistó a personal del área de Parques y Jardines de la administración municipal, quien informó que no se cuenta con estadísticas continuas de generación o recolección, pero ofreció un volumen estimado de las podas recolectadas estacionalmente. Fue posible realizar una visita de campo al área municipal de acopio de podas donde hubo oportunidad de entrevistar a operadores y de hacer una estimación visual de los volúmenes generados. Finalmente, se asistió a un curso de certificación para podadores privados con el fin de conocer la dinámica de la corta de podas por personal no municipal. En todas las instancias, se preguntó también sobre el manejo y destino que se daba a los residuos de la jardinería.

Se transcribieron las entrevistas realizadas, así como las notas de las observaciones de campo, y se formó una base de datos detallando las cantidades generadas por tipo de residuo y zona, estandarizándose las cantidades en unidades equivalentes (kg/ semana). Posteriormente, se calcularon los volúmenes requeridos de cada tipo de residuo (excretas ricas en $\mathrm{N}$ generadas en las granjas porcinas y la proporción de podas ricas en c) para lograr la relación $\mathrm{C} / \mathrm{N}$ inicial y humedad óptimas, para realizar el proceso de compostaje lo más adecuado posible (Rodríguez, \& Córdova 2006). 


\section{RESULTADOS}

\section{Flujo de residuos orgánicos asociados con la porcicultura}

Se encontraron cuatro zonas de producción porcícola en una franja periurbana del poniente de la ciudad. El cuadro 1 relaciona dichas zonas con el número de entrevistas obtenidas, el número de granjas donde no se consiguió entrevista y el número de granjas que están fuera de operación. Los entrevistados mencionaron que la ausencia de operadores se debía a que muchos de ellos trabajan en otras actividades económicas (construcción o maquiladoras), dejando la operación de las granjas en segundo término.

En cuanto a las granjas fuera de operación, explicaron que muchos de los porcicultores abandonaron esta actividad alrededor de 2008, a raíz de la violencia, y debido a las dificultades de obtener residuos alimenticios a partir de que en 2007 se reguló la recolección de los generados en los sectores comercial e industrial como una actividad exclusiva de empresas recicladoras certificadas por el Municipio. Previo a esto, los porcicultores recolectaban directamente, y de forma gratuita para ambas partes, residuos alimenticios de establecimientos comerciales e industriales como insumo para sus operaciones pecuarias. A partir de la regulación de esta recolección, las empresas recolectoras no están autorizadas a entregar los residuos alimenticios a los porcicultores, por lo que deben hacerlo a alguna empresa recicladora también certificada por el Municipio.

Esto ha generado un nuevo mercado en el manejo de los residuos orgánicos, ya que las empresas recolectoras cobran a los establecimientos una cuota de aproximadamente 60-70 pesos por cada tambo de 200 litros que recogen, y pagan a las recicladoras por depositarlos. Las recicladoras, a su vez, secan los residuos alimenticios al sol y, posteriormente, los envían al relleno sanitario. Las entrevistas revelaron que informalmente aún hay cierto flujo de residuos alimenticios desde los establecimientos directamente hacia los porcicultores, ${ }^{4}$ pero definitivamente es un flujo muy

4 Algunos porcicultores reportan que los establecimientos les llaman cuando el servicio formal de los recolectores es muy tardado. Otros indican que recolectan de forma con- 
reducido del original y, además, en la mayor parte de los casos, viene ahora con un costo para el porcicultor que varía entre $70 \mathrm{y}$ 100 pesos por tambo de 200 litros, lo cual ha transformado radicalmente las bases de la operación pecuaria. En resumen, se ha generado un nuevo mercado de manejo de residuos alimenticios en la localidad que afecta negativamente a los porcicultores y generadores de residuos alimenticios, y beneficia a un nuevo grupo de actores certificados en recolección y reciclaje. Es importante mencionar que, en su momento, se invitó a los porcicultores a inscribirse como recolectores y a dejar la porcicultura, y algunos de ellos sí lo han hecho. Pero en términos generales, el nuevo mercado está compuesto de nuevos actores.

Cuadro 1. Número de granjas porcícolas identificadas

\begin{tabular}{ccccc}
\hline Zonas & $\begin{array}{c}\text { Núm. de } \\
\text { granjas que se } \\
\text { entrevistaron }\end{array}$ & $\begin{array}{c}\text { Núm. de gran- } \\
\text { jas sin entre- } \\
\text { vistas }\end{array}$ & $\begin{array}{c}\text { Núm. de gran- } \\
\text { jas fuera de } \\
\text { operación }\end{array}$ & $\begin{array}{c}\text { Total de } \\
\text { granjas } \\
\text { por zona }\end{array}$ \\
\hline $\begin{array}{c}\text { 1. Granjas } \\
\text { Unidas }\end{array}$ & 10 & 4 & 12 & 26 \\
\hline $\begin{array}{c}\text { 2. Colonia } \\
\text { Fronteriza }\end{array}$ & 17 & 7 & 13 & 37 \\
\hline 3. El "Titanic" & 15 & 11 & 9 & 25 \\
\hline $\begin{array}{c}\text { 4. Ejido Santa } \\
\text { Elena }\end{array}$ & 8 & 3 & 12 & 23 \\
\hline
\end{tabular}

Fuente: elaboración propia con base en datos de campo (2014).

En el cuadro 2 se presentan los volúmenes de alimento que llegan a las zonas de estudio desde diferentes fuentes (recolectoresrecicladoras, restaurantes, centrales de abastos, casas-habitación, pequeños negocios y otras), identificando en la parte izquierda las cuatro zonas y registrando el total, en kilogramos por semana, de residuos orgánicos de entrada a las granjas. Es importante destacar que se aprecia una diferencia de fuentes de alimento en cada zona y que el mayor volumen proviene directamente de restaurantes, empacadoras (pequeños supermercados) y puestos de comida.

tinua los residuos de algunas empresas con las que han colaborado desde hace años. 
Cuadro 2. Volumen de alimento y residuos alimenticios que entran a las zonas de estudio (kg/semana)

\begin{tabular}{|c|c|c|c|c|c|c|c|}
\hline Zona & $\begin{array}{l}\text { Núm. } \\
\text { de porci- } \\
\text { nos }\end{array}$ & $\begin{array}{c}\text { Alimento } \\
\text { de } \\
\text { - reciclado- } \\
\text { ras } \\
(\mathrm{kg}) \\
\end{array}$ & $\begin{array}{c}\text { Granos } \\
\text { (maíz, } \\
\text { sorgo y } \\
\text { salvado) } \\
\text { (kg) }\end{array}$ & $\begin{array}{c}\text { Verduras/ } \\
\text { Mercados } \\
\text { de abas- } \\
\text { tos/Casas- } \\
\text { habitación } \\
\text { (kg) }\end{array}$ & $\begin{array}{c} \\
\text { Tortillas } \\
\text { Harina } \\
\text { (kg) }\end{array}$ & $\begin{array}{c}\text { Restauran- } \\
\text { tes/Puestos } \\
\text { de comida/ } \\
\text { Empacado- } \\
\text { ras } \\
\text { (kg) } \\
\end{array}$ & $\begin{array}{c}\text { Total } \\
(\mathrm{kg})\end{array}$ \\
\hline 1 & 182 & 2340 & 20 & 233 & 507 & 1600 & 4700 \\
\hline 2 & 604 & 12600 & 120 & 0 & 0 & 19606 & 32326 \\
\hline 3 & 460 & 400 & 760 & 400 & 60 & 12000 & 13620 \\
\hline 4 & 197 & 3000 & 105 & 0 & 0 & 4200 & 7305 \\
\hline Total & 1443 & 18340 & 1005 & 633 & 567 & 37406 & 57951 \\
\hline
\end{tabular}

Fuente: elaboración propia con base en información de entrevistas (2014).

En lo que se refiere al manejo de las excretas porcinas, la mayoría de los operadores entrevistados no llevan un control de los volúmenes generados, si bien algunos pueden dar alguna estimación aproximada. Tampoco hay un tratamiento sistemático de limpieza en los corrales ni un manejo formal de las excretas. La mayoría de los operadores dejan secar las excretas en los establos, mientras que otros las sacan y las tiran en terrenos aledaños, arroyos o en su propio terreno. Algunos canalizan las excretas por gravedad fuera de su terreno. Un solo entrevistado reportó el uso de aserrín para reducir la humedad y dar un tratamiento a las excretas, ${ }^{5}$ y otro mencionó que las llevaba al relleno sanitario, donde le cobraban doscientos pesos por la carga de una pick-up.

En el cuadro 3 se presentan las estimaciones de generación diaria de excretas porcinas en las granjas entrevistadas. La literatura (Ministerio de Agricultura y Ganadería, 2006) señala volúmenes promedio de producción diaria de excretas según la edad/ tamaño de porcinos. Aquí se desglosan los animales grandes (adultos, entre 68-90 kg) y chicos (en crecimiento, entre 16-30 kg) para hacer los cálculos.

5 Al integrar material rico en c y dejar airear la mezcla, esto representa un compostaje rudimentario. 
Cuadro 3. Generación diaria de excretas porcinas en las granjas entrevistadas

\begin{tabular}{cccccc}
\hline Zonas & $\begin{array}{c}\text { Núm. de } \\
\text { porcinos } \\
\text { grandes } \\
(68-90 \mathrm{~kg})\end{array}$ & $\begin{array}{c}\text { Núm. de } \\
\text { porcinos } \\
\text { chicos } \\
(16-30 \mathrm{~kg})\end{array}$ & $\begin{array}{c}\text { Excretas de } \\
\text { porcinos gran- } \\
\text { des } \\
\text { (5.15 kg/día) }\end{array}$ & $\begin{array}{c}\text { Excretas de } \\
\text { porcinos chicos } \\
(1.45 \mathrm{~kg} / \text { día })\end{array}$ & $\begin{array}{c}\text { Total de } \\
\text { excretas } \\
\text { (kg/día) }\end{array}$ \\
\hline 1 & 143 & 39 & 736.45 & 56.55 & 793 \\
\hline 2 & 416 & 188 & 2142.4 & 272.6 & 2415 \\
\hline 3 & 190 & 270 & 978.5 & 391.5 & 1370 \\
\hline 4 & 146 & 51 & 751.9 & 73.95 & 825.85 \\
\hline Total & 895 & 548 & 4609.25 & 794.6 & 5403.85 \\
\hline
\end{tabular}

Fuente: elaboración propia con base en datos obtenidos en entrevistas y promedios de generación de excretas porcinas en la literatura (Ministerio de Agricultura y Ganadería, 2006).

En la figura 3 se resumen y esquematizan los flujos de los biorresiduos que entran y salen del conjunto de granjas porcícolas entrevistadas. Del lado izquierdo, se muestran las fuentes de alimentos; en la parte central, las cuatro zonas de granjas; y del lado derecho, los volúmenes de excretas producidas. El grosor de las flechas y el tamaño de las figuras geométricas están relacionados con los volúmenes de residuos en cada flujo. Esta figura solo muestra los residuos asociados con las granjas entrevistadas, las cuales se estima que representan $65 \%$ del total de las granjas porcícolas de la zona periurbana poniente de la ciudad. 
Figura 3. Flujos de residuos orgánicos asociados con granjas porcícolas estudiadas

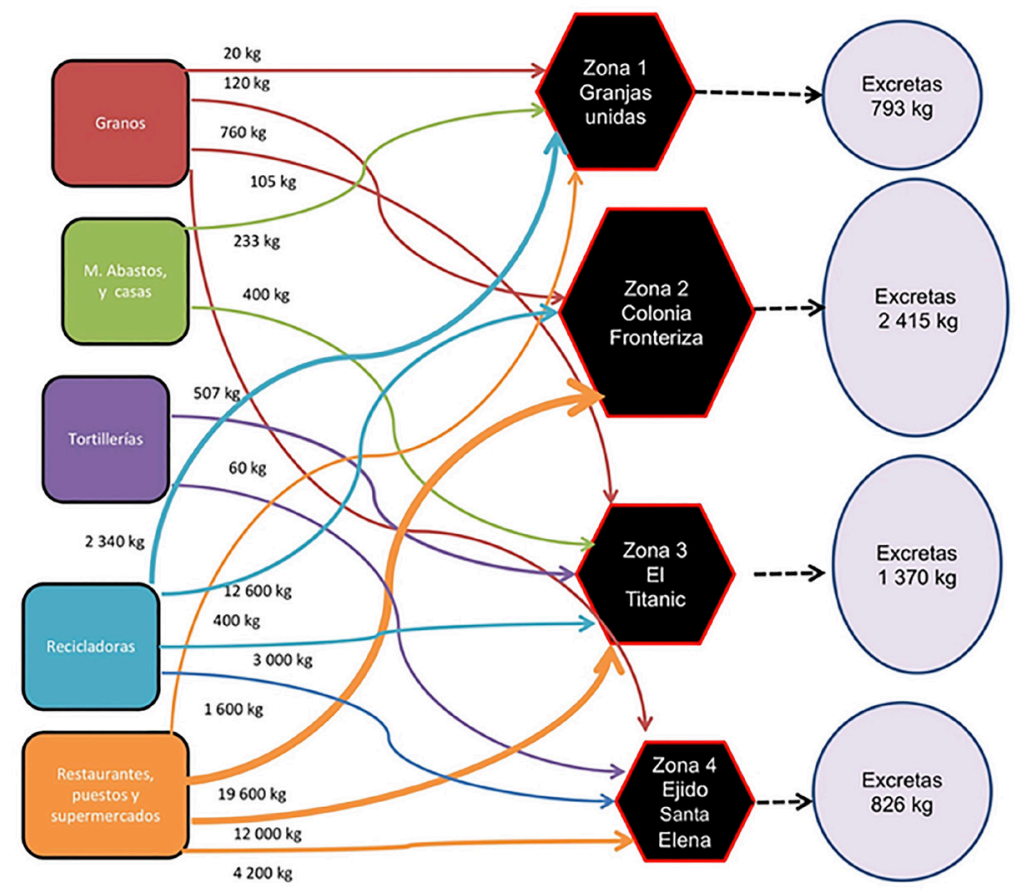

Fuente: elaboración propia con base en datos reportados en entrevistas y estimaciones de volúmenes de excretas, según el Ministerio de Agricultura y Ganadería (2006).

\section{FLUJO DE RESIDUOS ORGÁNICOS POR MANEJO DE ÁREAS VERDES PÚBLICAS}

Las áreas verdes públicas utilizan residuos orgánicos del Rastro Municipal como insumo para mejorar el suelo y generan residuos orgánicos de podas. En entrevista, el personal del Rastro Municipal estimó que se destinan veinte toneladas de lodo y estiércol, al año, al área de Parques y Jardines.

En el manejo municipal de podas tampoco se lleva un registro sistemático de pesaje o volúmenes generados. Sin embargo, el personal a cargo de las operaciones brindó una estimación de los 
volúmenes de las podas invernales generadas en las mil hectáreas de camellones y parques a su cargo. ${ }^{6}$ Estos volúmenes y su distribución mensual, se reportan en el cuadro 4. Las ramas gruesas se regalan a la población que las solicite como leña; lo demás se envía al relleno sanitario. Recientemente, se adquirió una trituradora que facilita el manejo de las podas. El cuadro 4 no representa el total de los residuos de podas generados en áreas públicas de la ciudad, puesto que en verano hay cortes de pasto y recolección de ramas pequeñas, de los cuales no se obtuvieron estimaciones volumétricas. Asimismo, existe un padrón de setenta personas autorizadas por el Municipio para cortar y recolectar podas de áreas privadas y entregarlas al relleno sanitario, pero similarmente a lo observado en otros flujos de residuos orgánicos, no se cuenta con un registro de los volúmenes manejados por los podadores privados y, en este caso, tampoco con una estimación.

Cuadro 4. Volúmenes de podas invernales generadas por la dependencia municipal Parques y Jardines

\begin{tabular}{cccccc}
\hline $\begin{array}{c}\text { Volumen diario (kg/ } \\
\text { día) }\end{array}$ & $\begin{array}{c}\text { Octubre } \\
2000\end{array}$ & $\begin{array}{c}\text { Noviembre } \\
4000\end{array}$ & $\begin{array}{c}\text { Diciembre } \\
4000\end{array}$ & $\begin{array}{c}\text { Enero } \\
3000\end{array}$ & $\begin{array}{c}\text { Febrero } \\
1000\end{array}$ \\
\hline $\begin{array}{c}\text { Total semanal (kg/ } \\
\text { semana) }\end{array}$ & 8000 & 16000 & 16000 & 12000 & 4000 \\
\hline
\end{tabular}

Fuente: elaboración propia con base en estimaciones del área de Parques y Jardines (2014).

Nota: se recolectan las podas cuatro veces por semana.

En la figura 4 se resume y esquematiza el flujo de los biorresiduos que entran y salen del manejo de las áreas verdes municipales. Del lado izquierdo, se muestra el volumen aproximado recibido del Rastro Municipal; y del lado derecho, el volumen de podas generadas. Esta figura solo muestra los residuos asociados con el manejo público de las áreas verdes municipales, específica-

6 Mil hectáreas (1000 ha) de camellones y parques es la estimación del personal de Parques y Jardines. El Plan de Desarrollo Urbano 2012 reporta 873 ha de áreas verdes para la ciudad, que no incluyen camellones. Si se contabilizara la superficie de camellones y se agregara a la de los parques, es probable que la cifra se acerque efectivamente a la estimación de 1000 ha que hace el personal de Parques y Jardines. 
mente podas de invierno, pues no incluye estimaciones de podas de verano ni las anuales generadas por particulares (aún en la vía pública).

Figura 4. Flujo de residuos orgánicos asociados con el manejo público de áreas

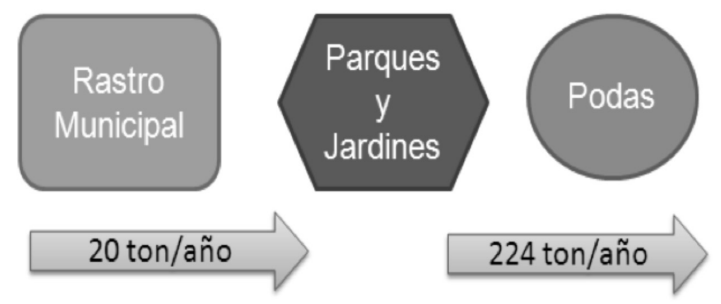

Fuente: elaboración propia con base en datos proporcionados en entrevistas (2014).

\section{ANÁLISIS DE MEZCLAS DE RESIDUOS PARA GENERACIÓN DE COMPOST, A PARTIR DE EXCRETAS PORCÍCOLAS Y PODAS MUNICIPALES}

Con el fin de estimar los volúmenes de diferentes tipos de residuos necesarios para la formulación de mezclas óptimas para compost, es necesario lograr proporciones de c/N de 30/1 y niveles de humedad de 40-60 \%. El cuadro 5 presenta los contenidos de c, N y humedad de los residuos de interés, según Sztern y Pravia (1999) y Rodríguez y Córdova (2006).

Cuadro 5. Contenido de N, C y humedad en estiércol de cerdos y madera

\begin{tabular}{cccc}
\hline Residuo & $\begin{array}{c}\% \mathrm{~N} \\
\text { de composición de composición }\end{array}$ & $\begin{array}{c}\% \mathrm{C} \text { de } \\
\text { composición }\end{array}$ \\
\hline Estiércol porcino & 0.300 & 6.00 & 92 \\
\hline Lodos activados digeridos & 0.47 & 7.38 & 75 \\
\hline Podas & 0.300 & 45.00 & 45 \\
\hline Estiércol bovino & 0.170 & 3.06 & 90 \\
\hline Fracción orgánica de RSU & 0.189 & 9.58 & 65 \\
\hline
\end{tabular}

Fuente: Sztern y Pravia (1999); Rodríguez y Córdova (2006). 
Con estos datos, se calcula que para el compostaje de 5403.85 kg/día de excretas porcinas son necesarios $3400 \mathrm{~kg} / \mathrm{semana}$ de podas (véase cuadro 6). Queda aún una humedad superior a la requerida para un proceso óptimo del compostaje (86 \% en lugar de $60 \%$ ), pero considerando el clima árido de la localidad es factible reducir la humedad inicial rápidamente con unos días de secado al sol y, posteriormente, con el volteo (aireación) requerido de la mezcla.

Cuadro 6. Formulación de mezcla óptima para compostaje de excretas porcinas semanales con podas municipales

\begin{tabular}{|c|c|c|c|c|}
\hline Residuos orgánicos & $\begin{array}{l}\text { Peso (kg/ } \\
\text { semana) }\end{array}$ & $\begin{array}{l}\% \text { N de com- } \\
\text { posición }\end{array}$ & $\begin{array}{l}\% \text { c de com- } \\
\text { posición }\end{array}$ & $\begin{array}{l}\text { \% H O de } \\
\text { compósición }\end{array}$ \\
\hline $\begin{array}{l}\text { Excretas de cerdo } \\
\text { (parámetros) }\end{array}$ & -- & 0.300 & 6.00 & 92.00 \\
\hline Podas (parámetros) & -- & 0.300 & 45.00 & 45.00 \\
\hline $\begin{array}{c}\text { Excretas } \\
\text { (valores calculados) }\end{array}$ & 37827 & 113.48 & 2269.62 & 34800.84 \\
\hline $\begin{array}{c}\text { Podas } \\
\text { (valores calculados) }\end{array}$ & 3400 & 10.2 & 1530 & 1530 \\
\hline $\begin{array}{c}\text { Suma de valores } \\
\text { calculados }\end{array}$ & 41227 & 123.68 & 3799.62 & 36330.84 \\
\hline $\mathrm{C} / \mathrm{N}$ & & & & 30.7 \\
\hline$\%$ de humedad & & & & 88 \\
\hline
\end{tabular}

Fuente: elaboración propia con datos de campo y parámetros de Sztern y Pravia (1999); Rodríguez y Córdova (2006).

Esto significa que existen suficientes podas municipales para brindar de material rico en $\mathrm{c}$ a las excretas porcinas todo el año. Las necesidades anuales de podas para este proceso de compostaje, serían de 176.8 toneladas (3400 kg/semana x 52 semanas/ año = 176.8 toneladas/año); y el municipio genera 224 toneladas en los meses de octubre a febrero. Aun considerando que aquí solo se reportan los volúmenes de excretas de aproximadamente $65 \%$ de las granjas, si se aumentaran en $35 \%$ los volúmenes de ambos tipos de residuo, se requeriría un total de 239 toneladas de podas anuales. Esto representa únicamente 15 toneladas más de 
la producción de los meses de invierno reportados, las cuales se generan fácilmente en otros meses del año.

La porcicultura podría aportar aproximadamente 1967 toneladas de excretas adicionales anualmente al área de Parques y Jardines para su aplicación en las áreas verdes urbanas, casi diez veces la cantidad que ya recibe del Rastro Municipal actualmente. Estas excretas podrían depositarse directamente en las áreas verdes (como es frecuente actualmente), pero su compostaje hace más benéfica su aplicación al suelo y, de paso, las sanitiza. Con 1987 toneladas de entrada de ambas fuentes de excretas, se podrían generar aproximadamente 894 toneladas anuales de compost. ${ }^{7}$ Para una aplicación de 17 ton/ha recomendadas para árboles y pastos (Rodríguez \& Córdova, 2006), 894 toneladas de compost alcanzarían para 52 hectáreas de áreas verdes, que es una mínima fracción de los parques y camellones a cargo del Municipio (aproximadamente 1000 ha en total). Es decir, no sobraría compost - factor que ha sido un elemento de fracaso en plantas de compostaje en nuestro país (Rodríguez \& Córdova, 2006).

\section{DISCUSIÓN}

\section{Factibilidad social e institucional}

Se ha establecido que existe una factibilidad técnica de generación de compost de las excretas porcinas, pues se producen suficientes residuos de podas municipales para lograr las condiciones óptimas para el compostaje ${ }^{8}$ y, además, se generarían volúmenes de compost fácilmente consumidos por el área de Parques y Jardines. En estos flujos estudiados hay residuos con manejo actual (podas) y residuos sin manejo (excretas porcinas). Lo ideal es dar un tratamiento a esas excretas para que no generen problemas de sanidad animal en las granjas, así como ambientales y de salud

7 Considerando un $45 \%$ de reducción en el volumen por pérdida de agua y dióxido de carbono durante el proceso de compostaje.

8 Existe un exceso relativo de podas que se pueden combinar con otros residuos orgánicos urbanos para producir compost (e.g., lodo de plantas de tratamiento de aguas residuales, fracción orgánica de los residuos sólidos domiciliarios, etcétera), pero ese análisis está fuera del alcance del presente trabajo. 
pública en la ciudad en general. Un proceso de compostaje bien manejado, puede lograr elevaciones de temperatura hasta los 55 ${ }^{\circ} \mathrm{C}$ durante cinco días, lo cual destruye patógenos en la mezcla y hace inocuo el producto final.

Ahora proseguiremos con un análisis social e institucional de la factibilidad.

Se les preguntó a los entrevistados, tanto porcicultores como del área de Parques y Jardines, si el compostaje sería de interés para ellos en el manejo de los flujos de residuos orgánicos. Ambos grupos respondieron positivamente y en ambos casos hay ejemplos de indicios en ese sentido. Un porcicultor adiciona regularmente aserrín a las excretas generadas en su granja "para reducir la humedad", lo cual representa el inicio en una formulación adecuada de materiales para el compostaje. Integrando a su práctica volteos con cierta frecuencia y verificando la relación $\mathrm{C} / \mathrm{N}$, se lograrían las condiciones óptimas para el compostaje. Por su parte, en el área de Parques y Jardines también expresaron interés en el compostaje y señalaron la compra de una trituradora para facilitar el manejo de las podas como un paso en ese sentido. Por otro lado, existe experiencia en compostaje para el mejoramiento de las áreas verdes urbanas en la Universidad Autónoma de Ciudad Juárez y en otra organización a nivel local, de manera que, de proceder a generarse el compost, estos actores tendrían a personas experimentadas a quienes recurrir. En lo que se refiere al espacio para realizar el compostaje, se pueden buscar terrenos cercanos a las granjas periurbanas, que pueden ser arrendadas a un costo reducido, o incluso pudieran existir terrenos municipales disponibles. Pero considerando que el resguardo del equipo requeriría de seguridad las veinticuatro horas, lo más factible sería transportar las excretas porcinas a algún terreno donde el área de Parques y Jardines hubiera establecido sistemas de control y vigilancia.

Así, pues, los elementos que hacen factible y viable el proceso de compostaje son: i) Interés de los actores necesarios; ii) Se cuenta con un uso identificado y específico para el compost; iii) Se tiene disponibilidad de terrenos para desarrollar el compostaje; iv) Existe el equipo mínimo para comenzar operaciones (trituradora); 
v) Se tiene experiencia local en compostaje, así como en su aplicación en áreas verdes urbanas. Hay algunos elementos del análisis institucional más complejos, como los siguientes: la generación de un mecanismo formal de recolección de excretas provenientes de las granjas porcícolas conllevaría revisiones sanitarias más regulares, así como la identificación de las granjas que emplean escamocha (residuos alimenticios) para alimentar a los cerdos. El uso de escamocha está prohibido por la NOM-037-ZOO-1995 como medida preventiva para evitar la transmisión de la fiebre porcina clásica en cerdos. Sin embargo, la literatura sugiere que cuando la escamocha se hierve a $100{ }^{\circ} \mathrm{C}$ durante treinta minutos, esta puede ser sanitizada, evitando, con ello, la generación de riesgos zoosanitarios. Incluso, en California, por ejemplo, existen permisos oficiales para que los porcicultores utilicen la escamocha como alimento, por lo que requieren de visitas oficiales de inspección en forma mensual (CDFA, 2013). Así, pues, la integración de las excretas porcinas a un programa municipal de compostaje probablemente tendría que acompañarse de un control más riguroso de las operaciones porcícolas. Y si ese control no existe actualmente, es que hay dificultades institucionales que no lo están permitiendo, las cuales pueden ser económicas, políticas, de capacidad institucional, etcétera. Una posibilidad, dentro de un esquema controlado de sanitización de la escamocha, es tratarla térmicamente para poder usarla posteriormente como alimento porcino, pero esto requeriría del establecimiento de un sistema funcional de sanitización, efectivamente controlado, y de la posterior distribución del producto tratado.

Finalmente, la operación exitosa de un programa de compostaje depende de una serie de factores técnicos, sociales, políticos, administrativos y económicos que han sido descritos por Rodríguez y Córdova (2006). Aquí queremos resaltar el aspecto administrativo que requiere de la dedicación explícita de recursos económicos, humanos y materiales para la operación de un programa municipal de compostaje -no solo la inversión inicial en infraestructura. Para que la propuesta que aquí se analiza sea exitosa en Ciudad Juárez, el gobierno municipal tendría que compro- 
meter estos recursos de forma continua. No son cuantiosos pero implican un compromiso por parte de la administración municipal, que no se puede dar por sentado, aun y cuando conlleve beneficios como la reducción del volumen de los residuos depositados en el relleno sanitario y la extensión de la vida útil de este, que en el mediano plazo representaría un ahorro financiero importante para el gobierno municipal. Este compromiso presupuestal representa otra complejidad institucional que debe ser abordada en un estudio adicional.

\section{CONCLUSIONES}

Existe información de campo limitada acerca de los flujos de residuos orgánicos en ciudades mexicanas. Describir y analizar dichos flujos es importante para la atención de diversas problemáticas urbanas. También es importante para estudiar el metabolismo urbano y proponer estrategias que conduzcan a cerrar los ciclos biogeoquímicos presentes en las ciudades. En este documento presentamos un análisis del flujo de residuos orgánicos asociados con la porcicultura en la zona urbana y periurbana de Ciudad Juárez, Chihuahua, incluyendo el flujo de residuos alimenticios humanos (escamocha) para la alimentación de los cerdos, así como el flujo de las excretas porcinas. Asimismo, incluimos un análisis del manejo de los residuos de jardinería (podas municipales) como fuente de c, para la formulación de mezclas adecuadas para realizar el proceso de compostaje. Se determinó que existen las cantidades suficientes de podas municipales para compostar todas las excretas porcinas y que existe la necesidad de utilizar el producto terminado (compost) en las áreas verdes municipales. Por otro lado, se determinó que hay interés de los actores en explorar el compostaje como una estrategia de manejo de los residuos estudiados, y que se cuenta con experiencia local en el proceso y aplicación de este fertilizante natural en las áreas verdes. Todos estos elementos apuntan hacia una alta factibilidad técnica y social para lograr establecer el compostaje localmente. Algunas complejidades institucionales que deberán atenderse incluyen el control 
sanitario de las operaciones porcícolas, el establecimiento de un arreglo funcional que garantice la sanitización de la escamocha, así como el compromiso de la administración municipal para implementar un programa de compostaje con la inversión continua requerida de recursos financieros, humanos e infraestructura.

Siguiendo la jerarquía de una GIRSU marcada por las 3 R, antes del reciclaje es importante promover su reúso. Tanto en los residuos orgánicos como en los inorgánicos es más eficiente reusar que reciclar. En este sentido, el metabolismo urbano será más eficiente si primero se promueve el reúso sanitizado de la escamocha en la porcicultura y después se procede a reciclar las excretas porcinas a través de un proceso de compostaje (o, en su caso, de biodigestión).

El recurso suelo se encuentra muy degradado en zonas urbanas. La incorporación del compost al suelo urbano ayuda a regenerar este recurso, al mismo tiempo que fomenta mejoras en las áreas verdes urbanas, que a su vez son elementos esenciales en el equipamiento urbano con efectos importantes sobre el bienestar social y el desarrollo económico local. De esta manera, la búsqueda de un metabolismo circular en la ciudad beneficia a diversas dimensiones del desarrollo urbano.

\section{REFERENCIAS}

Buenrostro, O., \& Israde, I. (2003). La gestión de los residuos sólidos municipales en la cuenca del lago de Cuitzeo, México. Revista Internacional de Contaminación Ambiental, 19(4), 161169.

California Department of Food and Agriculture (CDFA) (2013). Risks Associated with Feeding Raw or Improperly Cooked Food Waste to Swine.

Dajoz, R. (2002). Los ciclos biogeoquímicos. Tratado de ecología. España: Mundi-Prensa, 356-362.

Girardet, H. (1999). Creating Sustainable Cities. Resurgence Books, 324-366. 
Gobierno del Estado de Chihuahua (2012). Programa Estatal para la Prevención y Gestión Integral de los Residuos Sólidos Urbanos y de Manejo Especial para el Estado de Chihuahua. Universidad Autónoma de Ciudad Juárez, 129-162.

Grimm, N. B., \& Redman, C. L. (2004). Approaches to the Study of Urban Ecosystems: The Case of Central Arizona-Phoenix. Urban Ecosystems, 7(3), 199-213.

Marmolejo, L., Torres, P., Oviedo, E., Bedoya, D., Amezquita, C., Klinger, R., Albán, F., \& Díaz, L. (2009). Flujo de residuos: elemento base para la sostenibilidad del aprovechamiento de residuos sólidos municipales. Ingeniería y Competitividad, 11(2), 79-93.

Ministerio de Agricultura y Ganadería (2006). Programa Nacional de Cerdos PITTA-Cerdos. Gobierno de Costa Rica: Dirección de Programas Nacionales.

Moughtin, C., \& Shirley, P. (2005). Urban Design: Green Dimensions. Routledge.

Odum, E. P., \& Sarmiento, F. O. (1998). Ciclos de la materia y condiciones físicas para la existencia: ciclos biogeoquímicos. Ecología: el puente entre ciencia y sociedad. McGraw-Hill Interamericana Editores, 126-127.

Plan de Desarrollo Urbano (2012). Ciudad Juárez: Ayuntamiento de Juárez/Instituto Municipal de Investigación y Planeación.

Rodríguez, M., \& A. Córdova (2006). Manual de compostaje municipal: tratamiento de residuos sólidos urbanos (1. a ed.). México: Instituto Nacional de Ecología/Secretaría de Medio Ambiente y Recursos Naturales.

Secretaría de Medio Ambiente y Recursos Naturales (Semarnat) (2008). Diagnóstico básico y problemática para la gestión integral de residuos. Programa Nacional para la Prevención y Gestión Integral de los Residuos 2009-2012 (PNPGIR). México, 36-47. Sztern, D., \& Pravia, M. A. (1999). Manual para la elaboración de compost. Bases conceptuales y procedimientos. Presidencia de la República de Uruguay/ Organización Panamericana de la Salud. Recuperado de http://www.bvsde.paho.org/bvsars/ fulltext/compost.pdf 
Wackernagel, M., \& Rees, W. (1996). Our Ecological Footprint: Reducing Human Impact on the Earth. New Society Press, 223-248. 